\title{
MICRORGANISMOS ENCONTRADOS NO SISTEMA DE LODOS ATIVADOS APLICADO AO TRATAMENTO DO LICOR NEGRO
}

\author{
L. F. SANTOS ${ }^{1}$, T.C.B.PAIVA ${ }^{2}$ e F.T. SILVA $^{2}$ \\ Escola de Engenharia de Lorena - USP, ${ }^{1}$ Dep. de Química e ${ }^{2}$ Dep. de Biotecnologia \\ E-mail para contato: professorlucrecio@usp.br ou lucreciofabio@gmail.com
}

\begin{abstract}
RESUMO - O processo de lodo ativado consiste de uma massa ativa de microrganismos que fazem a degradação da matéria orgânica. Entre eles estão as bactérias, protozoários e metazoários. Sua resposta ao desenvolvimento dos organismos individuais é difícil de predizer, uma vez que estão susceptíveis às condições de alimentação, composição do despejo, $\mathrm{pH}$, temperatura e a própria competição entre eles. O lodo inicial usado no tratamento do licor negro, efluente oriundo da produção de nitrocelulose, foi obtido de uma indústria de papel e os experimentos foram realizados num reator de PVC, de $50 \mathrm{~L}$, equipado com três saídas, sistema intermitente (batelada), cujo suprimento de ar foi realizado com compressores e a concentração de $\mathrm{O}_{2}$ foi mantida em torno de $8 \mathrm{mg} / \mathrm{L}$. A presença de microrganismos foi monitorada através de microscópio eletrônico. Ocorreu alteração dos microrganismos durante a fase de adaptação. Após esta fase, o desenvolvimento se deu normalmente, com variedade e frequência condizentes com as operações de lodo ativado aplicado ao tratamento de esgotos domésticos.
\end{abstract}

Palavras-chaves: Efluente. Lodo Ativado. Microrganismo.

\section{INTRODUÇÃO}

Os processos biológicos são métodos de tratamento em que a remoção da matéria orgânica ocorre por meio da ação de microrganismos, que promovem a oxidação dos materiais biodegradáveis. Tais processos procuram reproduzir, em espaços predefinidos, racionalmente projetados e economicamente justificáveis, os fenômenos biológicos observados na natureza. A matéria orgânica complexa é transformada em substâncias simples, como sais minerais, gás carbônico e outros, caracterizando, assim, o fenômeno da autodepuração (Sant'Anna, 2013).

Os processos biológicos, aeróbios e anaeróbios, são amplamente empregados em sistemas de tratamento de águas residuárias. Em cada processo, há diferenças quanto ao crescimento microbiano (disperso ou aderido); quanto ao fluxo (contínuo ou intermitente) e quanto à hidráulica (mistura completa, fluxo pistão ou fluxo arbitrário). Para propiciar condições adequadas à microbiota envolvida no tratamento da água residuária, especial atenção deve ser dada aos fatores ambientais e aos parâmetros de projeto. Fatores como $\mathrm{pH}$, temperatura, nutriente e concentração de substrato influenciam no desenvolvimento dos microrganismos (Mendonça, 2002). 
Parâmetros como tempo de retenção celular $\left(\theta_{c}\right)$, tempo de detenção hidráulico (TDH), relação alimento/microrganismo $(\mathrm{A} / \mathrm{M})$ e a configuração do sistema têm grande importância na concepção da estação de tratamento de efluentes (Piveli e Seckler, 2002).

Segundo Figueiredo (2005), para o bom desempenho do sistema de lodo ativado é fundamental que a separação entre o lodo e a fase líquida, que ocorre no decantador secundário, seja rápida e eficiente.

Algumas condições são essenciais para a efetiva degradação da matéria orgânica, dentre elas a população de microrganismos ativos, o contato adequado entre estes e a matéria a ser degradada, a disponibilidade de oxigênio e nutrientes. As condições ambientais também devem ser favoráveis, principalmente em termos de $\mathrm{pH}$, temperatura e tempo de contato (Ferreira e Coraiola, 2008).

\subsection{Microbiologia do sistema de lodos ativados}

As bactérias, protozoários, metazoários e fungos são os principais organismos formadores do floco biológico do sistema de lodo ativado, sendo as bactérias os microrganismos de maior importância, em face de serem as principais responsáveis pela estabilização da matéria orgânica (Sant'Anna, 2013).

Bactérias: são os microrganismos mais importantes do processo de lodo ativado, pois, são responsáveis pela decomposição da matéria orgânica e formação do floco. Esses organismos ocorrem principalmente como bactérias saprófitas, isto é, elas obtêm nutrientes e energia para o seu crescimento pela progressiva estabilização e eventual mineralização dos compostos orgânicos dos despejos. No processo de lodo ativado, as bactérias se dividem em filamentosas e não filamentosas.

Protozoários: Depois das bactérias, os protozoários são os organismos mais numerosos no lodo ativado, quando em boas condições de operação. O principal grupo de protozoários encontrados no lodo ativado é ciliado. Eles normalmente representam aproximadamente 5\% do peso seco dos sólidos em suspensão presentes no tanque de aeração. Em ordem decrescente, segundo o "Water Pollution Research Laboratory" (WPRL, 1965), as espécies encontradas no processo de lodo ativado são: Aspidisca costata, Vorticella nebulifera, Vorticella aequilata, Vorticella microstoma, Vorticella companula, Opercularia coarctata, Trachelophyllum pusillum, Chilodonella uncinata, Uronema griseolum, Epistylis plicatilis, Aspidisca lynceus e Colpoda.

Metazoários: Em contraste com as bactérias e os protozoários, os metazoários (rotíferos, nematóides e anelídeos) são organismos pluricelulares. A reprodução dos metazoários depende das condições do ambiente em que estão presentes, podendo ser sexuada, assexuada ou alternando (WEF,1987). Dentre os metazoários, somente os micrometazoários possuem condições para se desenvolverem num ambiente com turbulência, como o verificado no processo de lodo ativado. Os metazoários mais frequentes nos processo de lodo ativado são os rotíferos, em particular os pertencentes aos gêneros Philodina roseolla e Rotaria citrinus, que geralmente são associados a lodos de sistemas com bom nível de 
depuração. Já os vermes (anelídeos, nematóides) são encontrados mais raramente, sendo representante desse filo o gênero Rhabditis.

Fungos: Os gêneros de fungos mais observados no lodo ativado são: Fusarium, Geotrichoides, Oospora, Phoma, Pulularia e Sporotrichum e vários gêneros carnívoros, tais como Zoophagus, Arthrobotrys e outros. Ocorrem especialmente em condições pouco verificadas no processo de lodo ativado (baixo $\mathrm{pH}$ e deficiente em nitrogênio). $\mathrm{O} \mathrm{pH}$ ótimo para a maioria das espécies gira em torno de 5, contudo, sobrevivem em $\mathrm{pH}$ entre 2 e 9. Sob condições adversas, os fungos podem dominar a comunidade e serem os maiores responsáveis pelo tratamento. Para a estabilização da matéria orgânica, os fungos são tão eficientes quanto às bactérias. Entretanto, a sua presença, como organismo predominante, cria dificuldades na separação do lodo no decantador secundário (Alem Sobrinho et al., 1999).

\subsection{Floco Biológico}

O floco do lodo ativado é constituído por fragmentos não digeridos, uma fração inorgânica, células mortas e, principalmente, por uma grande variedade de bactérias, que se concentram formando uma unidade estrutural mais ampla. A estrutura do floco é organizada por macroestruturas e microestruturas. A macroestrutura é formada por bactérias filamentosas e é considerada o esqueleto do floco. A microestrutura é a base do floco, sendo composta por agregados de células (Figueiredo, 2005).

Conforme reportado, alguns microrganismos são considerados indicadores das condições do processo de lodo ativado, cujos principais microrganismos presentes no sistema de lodo ativado, com a correspondente característica do processo, são mostrados na Tabela 1.

Tabela 1 - Microrganismos indicadores das condições de depuração do sistema de lodo ativado

\begin{tabular}{|c|c|}
\hline Microrganismo & Características do processo \\
\hline Predominância de flagelados e rizópodes & $\begin{array}{l}\text { Lodo jovem, característico de início de } \\
\text { operação ou idade de lodo baixa. }\end{array}$ \\
\hline Predominância de flagelados & $\begin{array}{l}\text { Deficiência de aeração, má depuração e } \\
\text { sobrecarga orgânica. }\end{array}$ \\
\hline Predominância de ciliados pedunculados e livres & Boas condições de operação \\
\hline Presença de Arcella (rizópode c/ teça) & Boa depuração \\
\hline Presença de Aspidisca costata (ciliado livre) & Nitrificação \\
\hline Presença de Trachelophyllum (ciliado livre) & Idade de lodo elevada \\
\hline $\begin{array}{l}\text { Presença de Vorticella micróstoma (ciliado } \\
\text { peduncular) e baixa concentração de ciliados } \\
\text { livres }\end{array}$ & Efluente de má qualidade \\
\hline Presença de anelídeos do gênero Aelosoma & Excesso de oxigênio dissolvido \\
\hline Predominância de filamentos & $\begin{array}{l}\text { Intumescimento do lodo ou "bulking" } \\
\text { filamentoso }\end{array}$ \\
\hline
\end{tabular}




\section{Materiais e métodos}

O efluente, oriundo da etapa de deslignificação da fabricação de nitrocelulose, previamente tratado quimicamente, foi submetido ao tratamento com lodo ativado (Santos, 2006). O lodo para dar início ao tratamento biológico foi cedido pela indústria papeleira Kimberly Clark Brasil (KCB), localizada em Cruzeiro/SP. O monitoramento de bactérias, protozoários ciliados, nematóides e rotíferos, foi realizado diariamente, por meio de microscópio eletrônico, marca OLYMPUS, modelo PX-50, com captura de imagem.

O tratamento biológico foi realizado num reator de mistura completa, de PVC (50 L), equipado com três saídas (batelada), que incorporou todas as unidades de processo, normalmente associadas ao processo convencional de alimentação contínua (Von Sperling, 1997). Os ciclos foram de 12 horas, com enchimento (30 min), reação (10 h), repouso (1h) e descarte (30 min), cuja representação esquemática é mostrada na Figura 1.

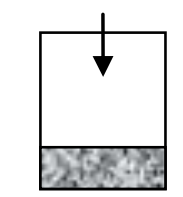

Enchimento

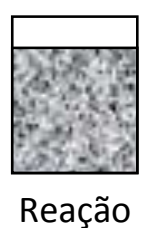

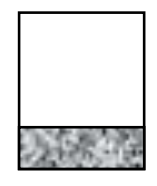

Repouso

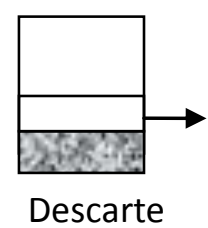

Descarte

Figura 1 - Representação esquemática das fases de um ciclo do reator batelada, compreendendo as fases de enchimento, reação, repouso e descarte.

Antes de iniciar o tratamento, o lodo biológico foi adaptado com o objetivo de garantir melhores condições para os microrganismos degradarem a matéria orgânica contida no efluente em estudo. A adaptação do lodo ao efluente foi realizada fazendo-se a alimentação do reator, nos dois primeiros dias, com o efluente diluído, conforme mostra a Tabela 2.

Tabela 2 - Proporção entre efluente de polpação alcalina e água de diluição, para adaptação do lodo, com ciclo de 12 horas

\begin{tabular}{cccc}
\hline Tempo & Horário de alimentação do reator & Efluente (\%) & Água (\%) \\
\hline \multirow{2}{*}{$1^{\mathrm{o}}$ dia } & $08 \mathrm{~h} 00 \mathrm{~min}$ & 25 & 75 \\
& $20 \mathrm{~h} 00 \mathrm{~min}$ & 50 & 50 \\
\hline \multirow{2}{*}{$2^{\mathrm{o}}$ dia } & $08 \mathrm{~h} 00 \mathrm{~min}$ & 75 & 25 \\
& $20 \mathrm{~h} 00 \mathrm{~min}$ & 100 & - \\
\hline
\end{tabular}

A partir da quarta alimentação, no segundo dia, até o final do tratamento foi adicionado ao reator biológico $100 \%$ de efluente tratado quimicamente. O descarte de efluente sempre se deu pela válvula central do reator, o qual foi recomposto com efluente a ser tratado. Foram adicionadas ao reator soluções de uréia e ácido fosfórico, procurando manter uma relação DBO:N:P de 100:5:1. O reator foi mantido em operação por 180 dias. As amostras para análise microscópica foram coletadas sempre uma hora após a alimentação do reator biológico. Foram também realizadas análises de $\mathrm{pH}$, Cor, DQO, DBO, COT, SS, SSF, SSV, RS, nitrogênio total, fósforo e ensaios de toxicidade, cujos tratamentos dos dados foram discutidos em outro artigo deste autor. 


\section{RESULTADOS E DISCUSSÃO}

A literatura é carente de informações quanto à microfauna existente no tratamento de efluentes industriais, principalmente, no que se refere ao tratamento de efluentes oriundos do processamento de materiais lignocelulósicos. O objetivo do trabalho não foi identificar com precisão a microfauna existente no lodo ativado empregado no tratamento de efluente industrial, mas sim tê-la como ferramenta de monitoramento do sistema. Diferentes tipos de microrganismos foram observados, e os principais são mostrados nas Figuras 2(a-f ) e 3(a-f).
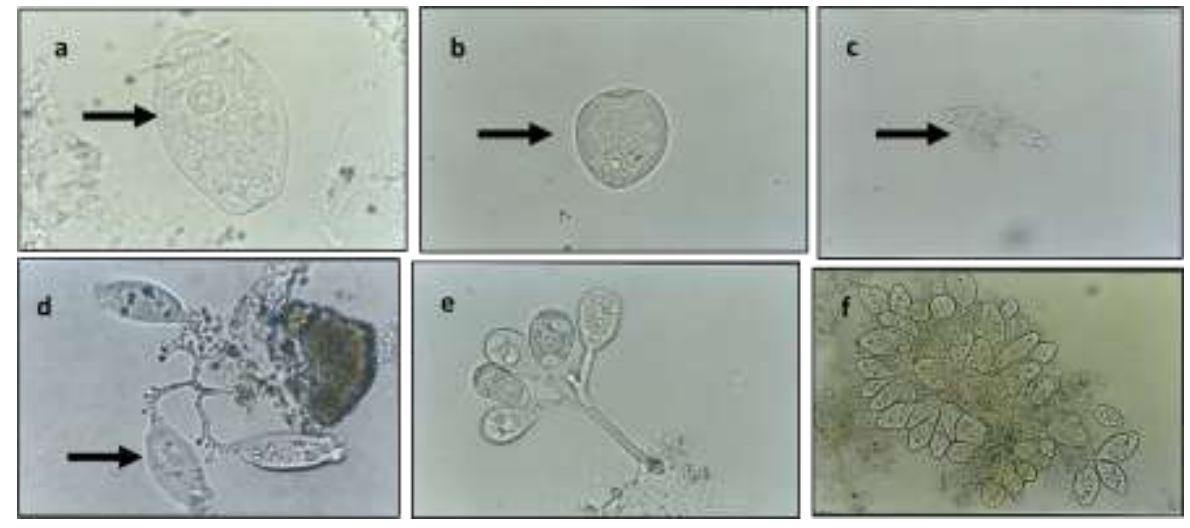

Figura 2 - Microrganismos observados no licor misto do tratamento do efluente de polpação alcalina - luz comum, ampliação (a, b, d, e) 400X, (c, f) 200X: a - ciliado livre semelhante a Monodinium sp; b - semelhante a Chilodonella sp; c, d - Ciliados semelhantes Opercularia coarctata; e - colônia pedunculada semelhante a Opercularia p; f - colônia de ciliados fixos semelhante a Epistylis SP.

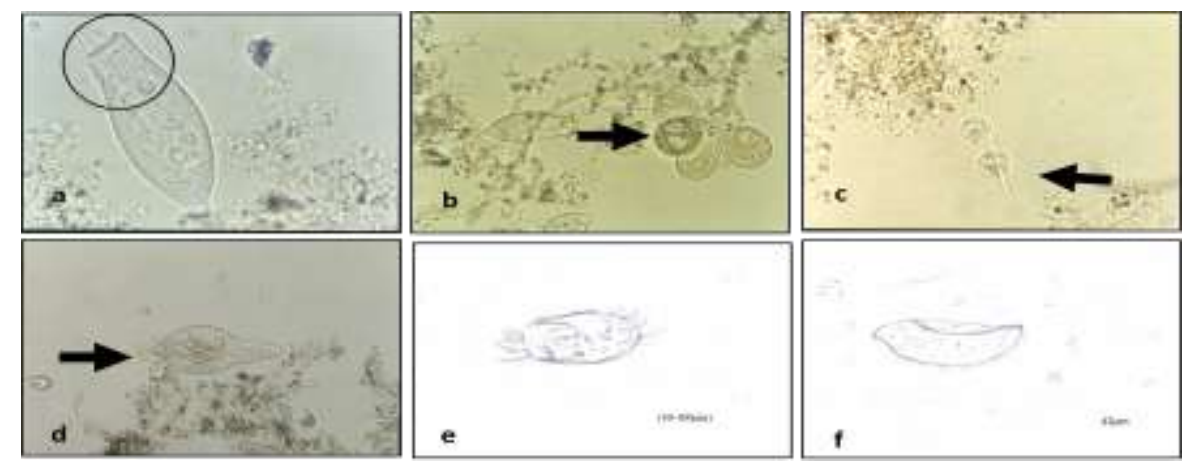

Figuras 3 - Microrganismos observados no licor misto do tratamento do efluente de polpação alcalina - luz comum, ampliação (a, b, c d) 200X: a - pertence a uma colônia de ciliados semelhante a Epistylis sp; b - colônia pedunculada semelhante a Vorticella sp; c - semelhante a Chlamydomonas $\mathrm{sp} ; \mathrm{d}$ - semelhante a Rotaria citrinus; e - semelhante a Aspidisca costata; $\mathrm{f}$ - semelhante a Chilodonella uncinata. 
A observação microscópica de formas de vida no lodo ativado é prática comum e muito difundida, pois, os tipos de organismos presentes no sistema podem ser relacionados à eficiência da planta e a qualidade do efluente final (Bento et al., 2005).

Ao longo deste trabalho, observou-se a formação de flocos, cujas características estruturais não apresentaram variações relevantes. Segundo Von Sperling (1997) e Figueiredo (2005), a formação de flocos em sistemas de lodos ativados é fundamental para a remoção da matéria orgânica. Não é apenas a propriedade dos organismos de estabilizarem a matéria orgânica que torna este sistema eficiente, mas, também, a propriedade que os organismos possuem para se organizarem na unidade estrutural do floco, promovendo a separação deste do líquido por simples sedimentação. Esta característica viabilizou a execução deste estudo em sistema batelada e a obtenção de um efluente final clarificado e com baixos valores de carga orgânica.

Foram observadas, também, não em grande quantidade, bactérias filamentosas. Pujol e Canler (1992) reportam que quando os organismos filamentosos dominam a competição entre espécies, forma-se uma macroestrutura filamentosa que prejudica a sedimentabilidade dos flocos. Esse fenômeno é conhecido como intumescimento ou "bulking" e é um problema complexo, que atinge de 20 a $40 \%$ das estações de tratamento. Por outro lado, quando não há quantidade suficiente de bactérias filamentosas, forma-se uma microestrutura que resulta em flocos de dimensões muito pequenas, os quais ficam dispersos na fase líquida, dificultando a sedimentação, esse problema é conhecido como "pinpoint".

Várias outras bactérias filamentosas têm sido encontradas em sistemas lodo ativado, dentre elas as mais comuns são Microthrix parvicella, Thiothrix e a Sphaerotilus natans (Cetesb, 1989; Figueiredo, 2005). Segundo Eikelboom (2000), os principais motivos para o aparecimento das bactérias filamentosas em sistema de lodo ativado são: escassez de nutrientes, baixa concentração de oxigênio dissolvido, baixa carga orgânica e elevada carga de compostos de baixa massa molar $(<1000 \mathrm{~g} / \mathrm{mol})$. Durante a fase experimental, a quantidade de nutrientes foi mantida na proporção 100:5:1 (DBO:N:P) e, segundo Santos (2001), esse tipo de efluente é constituído por compostos de alta massa molar, o que indica que a quantidade de bactéria filamentosas detectadas foram benéficas para o tratamento.

Protozoários estiveram presentes na maioria das amostragens. A presença de certos tipos de protozoários (flagelados) no meio indica efluente final de boa qualidade. Muitas espécies de Vorticella (ciliado pedunculado) ocorrem em sistemas operando com boa eficiência, juntamente com Opercularia e Aspidisca.

Observou-se também a presença de Aspidisca costata, que indica processo de nitrificação, uma vez que estes se alimentam de bactérias nitrificadoras. A presença ou ausência de determinado protozoário no lodo, por si só, não tem grande significado. Conclusões baseadas na população de protozoários, sobre o bom ou mau funcionamento de sistemas de lodo ativado, só poderão ser obtidas se for levada em conta a variação das populações dominantes ao longo do tempo. Em síntese, os protozoários são importantes para clarificação do efluente (Alem Sobrinho et al., 1999). 
Segundo Madoni et al. (1993), as espécies Vorticella micróstoma, Vorticella octava e Opercularia sp são predominantes quando as condições do sistema de tratamento são desfavoráveis, ou seja, há escassez de oxigênio, efluente com elevada DBO e não existem condições para que a nitrificação aconteça. Neste estudo, a presença de Vorticella e Opercularia não foi constante. A presença de outros indivíduos e a manutenção do nível de oxigenação $(8 \mathrm{mg} / \mathrm{L})$, possivelmente, contribuíram positivamente no desempenho do sistema.

A presença de ciliados fixos e livres, juntamente com rotíferos e nematóides, foram frequentes, demonstrando que o sistema de lodo ativado atingiu seu ponto ótimo de operação, corroborado pela boa qualidade do efluente final. Assalin (2005) obteve resultados satisfatórios, quando trabalhou com sistema combinado: Ozônio e lodo ativado para tratamento de efluente de indústria papeleira, onde observou que, durante a fase experimental, a quantidade de ciliados fixos e livres permaneceu alta.

Mendonça (2002) fez o monitoramento de um sistema de lodo ativado, utilizado para tratar esgoto doméstico, e constatou que os citados ciliados foram os mais frequentes. Isto indica que parte da microfauna do lodo ativado, utilizado para tratar efluente industrial, é semelhante àquela desenvolvida no lodo ativado para tratamento de esgoto doméstico. Tais espécimes também foram observados por Santos (2006) ao utilizar o lodo oriundo da indústria papeleira KSB, cujo sistema industrial de tratamento apresentava boas condições de operação.

\section{CONCLUSÃO}

Após várias semanas de acompanhamento do sistema de lodo ativado, utilizado para tratar o efluente oriundo da etapa de deslignificação da fabricação de nitrocelulose (licor negro), pré-tratado quimicamente, constatou-se que a variedade e frequência dos microrganismos observados durante o monitoramento biológico foram condizentes com as operações do sistema de lodo ativado, sendo semelhantes aos encontrados no tratamento de esgoto doméstico.

A identificação do grupo de microrganismos dominantes, presentes na microbiota do lodo, permitiu diagnosticar o estado de funcionamento do processo de lodo ativado no tratamento de efluente industrial como substrato. Os exames microscópicos ajudaram a avaliar a condição da biomassa e a sedimentabilidade do lodo durante os ciclos de tratamento.

Atenção especial deve ser dada à fase de adaptação, pois inicialmente, usando o efluente tal qual, ou seja, sem o tratamento químico prévio, a biota foi afetada ao ponto de se falência do sistema. Porém a fase de adaptação usando o efluente tratado quimicamente foi frutífera.

\section{REFERÊNCIA BIBLIOGRÁFICA}

ALEM SOBRINHO, P. et al. Microbiologia e controle do processo de lodos ativados e suas variações. Campinas/SP: Fundação André Tosello. p. 1 - 13 (Apostila), 1999. 
ASSALIN, M.R. Tratamento do efluente de indústria papeleira por processo combinado: ozônio e lodo ativado. 2005 (Tese de doutorado). Universidade Estadual de Campinas. Campinas. 2005.

BENTO, A.P.; SEVERINO, P.H.; PHILIPPI, L.S.; REGINATTO, V.; LAPOLLI, F.R. Caracterização da microfauna em estações de tratamento de esgotos do tipo lodos ativados: um instrumento de avaliação e controle. Engenharia Sanitária e Ambiental. vol. 10 - n 4. p 329 - 338. out./dez. 2005.

COMPANHIA DE TECNOLOGIA DE SANEAMENTO AMBIENTAL - CETESB: Microbiologia de lodos ativados. São Paulo/SP. 23 p. Série Manuais. 1989.

EIKELBOOM, D.H. Process control of activated sludge plants by microscopic investigation. Londres/RU: Asis/IWA. 156 p. 2000.

FERREIRA, F.D.; CORAIOLA, M. Eficiência do lodo ativado em fluxo contínuo para tratamento de de esgoto. Ver. Acad., Ciênc. Agrár. Ambient. Curitiba. v. 6. n 2. p. 259 -279. abr/jun. 2008.

FIGUEIREDO, M.G. Microbiologia de lodos ativados e lagoas aeradas. Expolabor. Seminário. Agosto. 2005.

MADONI, P.; DAVOLI, D.; CHIERICI, E. Comparative analysis of the activated sludge microfauna in several treatment works. Water Research. v. 27. n. 9. p. 1485 - 1491. 1993.

MENDONÇA, L.C. Microbiologia e cinética de sistema de lodos ativados como póstratamento de efluente de reator anaeróbio de leito expandido. 2002 (Tese de doutorado). Universidade de São Carlos/USP. São Carlos. 2002.

PIVELI, R.P.; SECKLER, S.F.F. Concepção de estações de tratamento de esgotos sanitários. São Paulo: Escola Politécnica/USP. 240 p. (Apostila). 2002.

PUJOL, R.; CANLER, J.P. Biosortion and dynamics of bacterial populations in activated sludge. Water Research. v. 26. n. 2. p. 209 - 212. 1992.

SANTOS, L.F., Caracterização e tratamento de efluentes da fabricação de nitrocelulose. FAENQUIL. Lorena/SP. 102 p. (Tese de Doutorado). 2006.

SANT'ANNA, G. L. Jr. Tratamento biológico de efluentes: fundamentos e aplicações. Ed. Interciência. 2 ed. Rio de Janeiro/RJ. 418p. 2013.

VON SPERLING, M. Lodos ativados: Princípios do tratamento biológico de águas residuárias. 1 ed. .Belo Horizonte. Departamento Engenharia Sanitária e Ambiental (DESA). v. 4. 416 p. 1997.

WEF - Activated sludge. Manual of practice. OM-9. Alexandria/USA: Water Environment Federation. 1987.

WPRL - Water Pollution Research Laboratory. The role of protozoa in activates sludge. Stevenage/England. 1965. 